\title{
A Theoretical Analysis for n-species Competition for Aphid Population in Limited Resources: A Modeling Study
}

\author{
Rajan K Sharma ${ }^{1}$, Shyam Sundar ${ }^{2, *}$, D. Kandu ${ }^{3}$ \\ ${ }^{1}$ Department of Mathematics, PSITCOE, Kanpur (U.P.), India \\ ${ }^{2}$ Department of Mathematics, P S Institute of Technology, Kanpur (U.P.), India \\ ${ }^{3}$ Department of Mathematics, M.M.M. Engineering College, Gorakhpur (U.P.), India \\ *Corresponding author: ssmishra_75@yahoo.co.in \\ Received April 03, 2014; Revised May 14, 2014; Accepted May 14, 2014
}

\begin{abstract}
In this paper, we have discussed a mathematical model for the competition in n-species aphid population for a limited resource and their limiting behavior is studied as time approaches to infinity. Aphids are among the most conspicuous and important pests in green houses and crops. It is assumed that aphids excrete honeydew and cover an area $\int_{0}^{t} P_{r}(s) d s$ by it's saliva at time ' $t$ ' which then form a weak cover on the leaf surface preventing the individuals from further sucking and movement and therefore causing deaths due to starvation. It means that the mortality rate of aphids become very high in the environment by honeydew excretions of other aphids. Analytically, it has been shown that how aphid population grows with time ' $t$ '.
\end{abstract}

Keywords: aphid population, environment, limited resources, Voltra model, $n$-Species, competition

Cite This Article: Rajan K Sharma, Shyam Sundar, and D. Kandu, "A Theoretical Analysis for n-species Competition for Aphid Population in Limited Resources: A Modeling Study." American Journal of Applied Mathematics and Statistics, vol. 2, no. 3 (2014): 157-159. doi: 10.12691/ajams-2-3-10.

\section{Introduction}

Aphids are plant lice small, soft-bodied sap-sucking insect pests in size from 1 to $7 \mathrm{~mm}$ with long legs and antennae. Aphids are most destructive insect pests have a wide host range significantly affect various field crops, fruits and vegetables [2]. Aphids are generally divided in to two sub-groups known as green-flies and black-flies and they contain different type of colors such as yellow, pink, and white, etc. Further, more than five hundreds species of aphid population has been found in east part of India. Aphid discharges lethal mucilaginous material, called saliva, smeared over the surface of the leaf preventing the individuals from further sucking and movements causing deaths due to hunger. Some species inject their saliva in to plant roots and slowly damaged the plants and attack a wide range of plant hosts. Some species when moving from one plant to other they spread out plant virus diseases, which has been seen in some soft fruits, such as strawberry and some vegetables such as tomatoes, beets, brinjals, sweet peas, etc. in a similar manner as in wheat $[1,5,14,15]$. Some aphid species attack different parts of plants other than leaves. The behavior of beet root aphid penetrate in to the soil and attacks beet roots during most of their life, causing beet plants to faccid and occasionally die if growth rate of aphid population is very high. Aphids are easily driven to death when weather is not according to their survival. Aphids are infertile in extreme temperature because due to higher temperature their symbiotic bacteria are killed on which some aphids are dependent [13,16]. The population growth of Soya been, aphin glyeines under varying labels of predator exclusion has been studied $[8,10]$.

Several investigations have been made to study the dynamics of aphid population by using mathematical models [3,4]. In experimental observations it is depicted that the total number of individuals in the population of Aphis fabae rapidly increased at the beginning, reaching its maximum on the $5^{\text {th }}$ day and then decreased rapidly as a high consequence of mortality of the aphids [11]. The first and the simplest law of population growth of a species was given by [9] as follows,

$$
\frac{d P}{d t}=k P
$$

from which we get

$$
P=P_{0} e^{k t}
$$

where $P(t)$ denotes the population at time $t, P_{0}$ is the population at time $t=0$ and $k$ is growth rate of population. The Malthusian growth equation implies that $P \rightarrow \infty$ as $t \rightarrow \infty$ but later on it has been suggested that 
crowding affects exist due to excessive demands on a limited food supply, [12]. He demonstrates that fecundity decreases and even raising deaths due to starvation. It is assumed that due to crowding, the growth rate $k$ is reduced by some proportion of the population $P$. Thus, the equation of the population growth of a single species is given by

$$
\frac{d P}{d t}=(k-b P) P
$$

The population $P$ asymptotically approaches to a limiting value $\frac{k}{b}$ (known as carrying capacity) for $k>0$ as $t \rightarrow \infty$.

In these problems, the population of only one biological species has been taken into account. It has been observed that a number of species are competing for a limited resource and the population density of one species may affect the growth rate of the other. In view of the above, we have established a mathematical model for n- species competition for aphid population on plant and studied their limiting behavior for limited resources as time approaches to infinity under a particular set of environmental conditions.

\section{2. n- Species Competition Model}

In a habitat, under consideration, internal competition in a species for limited resources of aphid population is taken into account to describe the phenomenon of nspecies competition model, [6,7,17]. In the proposed model, we assume that $P_{r}$ is the density of aphid population at time $t$ of $r^{\text {th }}$ species. Let $k_{r}>0$ denotes the growth rate of $r^{\text {th }}$ pecies in the absence of other species and $b_{r s}>0$ is the effect of the density of $s^{\text {th }}$ species on the population growth rate of $r^{\text {th }}$ species. Let the area covered by its saliva at time $t$ is proportional to the integral $\int_{0}^{t} P_{r}(s) d s$ then the dynamics of the system is given by the following differential equation,

$$
\frac{d P_{r}}{d t}=\left(k_{r}-\sum_{s=1}^{n} b_{r s} P_{s}\right) P_{r}-k P_{r} \int_{0}^{t} P_{r}(s) d s
$$

where, $r=1,2,3 \ldots n$ and $k$ is positive constant.

To get the solution of non linear differential equation (4) we assume that there are some environmental conditions under which the effect of density of one species on the growth rate of other species is the same as the effect of the density of a species on its own growth rate. From the equation (4) we get,

$$
\begin{gathered}
\frac{d P_{1}}{d t}=\left(k_{1}-b_{11} \bar{P}\right) P_{1}-k P_{1} \int_{0}^{t} P_{1}(s) d s \\
\frac{d P_{2}}{d t}=\left(k_{2}-b_{22} \bar{P}\right) P_{2}-k P_{2} \int_{0}^{t} P_{2}(s) d s
\end{gathered}
$$

$$
\frac{d P_{n}}{d t}=\left(k_{n}-b_{n n} \bar{P}\right) P_{n}-k P_{n} \int_{0}^{t} P_{n}(s) d s
$$

where $\bar{P}=P_{1}+P_{2}+\ldots+P_{n}$.

In the following, we investigate the competitive result for two different types of species (i.e. $i$ nd $j$ ).

Thus, we can write,

$$
\frac{d P_{i}}{d t}=\left(k_{i}-b_{i i} \bar{P}\right) P_{i}-k P_{i} \int_{0}^{t} P_{i}(s) d s
$$

and

$$
\frac{d P_{j}}{d t}=\left(k_{j}-b_{j j} \bar{P}\right) P_{j}-k P_{j} \int_{0}^{t} P_{j}(s) d s
$$

Now, assuming, $\quad N(t)=\int_{0}^{t} P_{i}(s) d s \quad$ and $M(t)=\int_{0}^{t} P_{j}(s) d s$, we have,

$$
\frac{d P_{i}}{d t}=\left(k_{i}-b_{i i} \bar{P}\right) P_{i}-k P_{i} N(t)
$$

and

$$
\frac{d P_{j}}{d t}=\left(k_{j}-b_{j j} \bar{P}\right) P_{j}-k P_{j} M(t)
$$

Multiplying (5) and (6) by $\frac{1}{b_{i i} P_{i}}$ and respectively and then on subtraction we have,

$$
\frac{d}{d t}\left\{\log \left(\frac{P_{i}^{\frac{1}{b_{i i}}}}{\frac{1}{P_{j j}}}\right)\right\}=c_{i j}-k\left\{\frac{N(t)}{b_{i i}}-\frac{M(t)}{b_{j j}}\right\}
$$

where

$$
\frac{k_{i}}{b_{i i}}-\frac{k_{j}}{b_{j j}}=c_{i j}
$$

Then the integration of the above differential equation leads to

$$
\log \left(\frac{P_{i}^{\frac{1}{b_{i i}}}}{\frac{1}{P_{j}^{b_{j j}}}}\right)=c_{i j} t-k \int\left\{\frac{N(t)}{b_{i i}}-\frac{M(t)}{b_{j j}}\right\} d t+\log \lambda
$$

Where $\lambda$ being the constant of integration,

$$
\frac{P_{i}^{\frac{1}{b_{i i}}}}{P_{j}^{\frac{1}{b_{j j}}}}=\lambda e^{c_{i j} t-k \int\left\{\frac{N(t)}{b_{i i}}-\frac{M(t)}{b_{j j}}\right\} d t}
$$


It is noted from (8) that,

$$
\frac{\left(P_{i}\right)_{0}^{\frac{1}{b_{i i}}}}{\left(P_{j}\right)_{0}^{\frac{1}{b_{j j}}}}=\lambda
$$

where $\left(P_{i}\right)_{0}$ and $\left(P_{j}\right)_{0}$ are the value of $P_{i}$ and $P_{j}$ at time $t=0 \quad$ that is, the initial stage of observation period.

\section{Results and Discussion}

From equation (8), we note the following two cases,

\section{Case I.}

$$
\text { If } c_{i j}>0 \text { then } \frac{P_{i}^{\frac{1}{b_{i i}}}}{P_{j}^{\frac{1}{b_{j j}}}} \rightarrow \infty \text { as } t \rightarrow \infty \text {. }
$$

This implies that $P_{j} \rightarrow 0$, thus we may say that the $j^{\text {th }}$ species become extinct.

\section{Case II.}

$$
\text { If } c_{i j}<0 \text { then } \frac{P_{i}^{\frac{1}{b_{i i}}}}{P_{j}^{\frac{1}{b_{j j}}}} \rightarrow 0 \text { as } t \rightarrow \infty \text {.This implies that }
$$

$P_{i} \rightarrow 0$, thus we may say that $i^{\text {th }}$ species becomes extinct.

\section{Conclusion}

In this paper, we have studied the behavior of the model system of $n$-species competition among aphid population. If we identify the effect of $i^{\text {th }}$ species on $j^{\text {th }}$ species and $j^{\text {th }}$ species on $i^{\text {th }}$ species then the competition tensor helps us to predict the behavior of the species of aphid population as the time approaches to infinity. From (7), it can easily be seen that the competition tensor $c_{i j}$ is a skew- symmetric tensor (since $c_{i j}=-c_{j i}$ ) and the diagonal elements of the matrix $\left[c_{i j}\right]$ are zero. In view of the cases I and II, we see that if any of the quantity $c_{i 1}, c_{i 2} \ldots c_{i n}$ is negative, the $i^{\text {th }}$ species goes to extinction and we will be left with $n-1$ rows. The interaction of aphid species would continue, till it is left with one row.

\section{References}

[1] Ahamad, K. J., Malik, N. A., Akhtar, A. S. and Hamza, M. Varietal resistance in wheat varieties/lines and sowing date effect on aphid population, J. Agric. Res., 44(3), 215-218, 2006.

[2] Aheer, G. M., Ali, A and Munir, M., Abiotic factors effect on population fluctuation of a late aphid in wheat, J. Agric. Res., 46(4), 367-371, 2008.

[3] Barlow, N. D., Modelling aphid population, New Zeland J .Ecol. 4 52-55, 1981.

[4] Barlow, N. D. and Dixon A. F. G., Simulation of lime aphid population dynamics, Centre for Agricultural Publishing and Documentation - Simulation Monographs, Wageningen, 1980.

[5] Jarosik, V., Honek, A. and Tichopad, A., Comparison of field population growths of three cereal aphid species on winter wheat plant, Protect. Sc., 39(2), 61-64, 2003.

[6] Jones, D. S. and Sleeman, B. D., Differential Equations and Mathematical Biology, George Allen and Unwin, London, 1981.

[7] Kapur, J. N., Mathematical Modeling, Wiley Eastern Ltd., New Delhi, 1989.

[8] Kobayashi, M., Nabata, H. and Murai, T., Testing soybean antibiosis to three clones of soybean aphid, Aphis glycines (Hemiptera: Aphididae) using sprouts and leaflets, Applied Entomology and Zoology, 48 (3), 295-300, 2013.

[9] Malthus, T. R., An essay on the principle of population, Johnston, London, 1798.

[10] Meihls, L. N., Clark, T. L., Bailey, W. C. and Ellersieck, M. R. Population growth of soybean aphid, aphin glycines under varying levels of predator exclusion, Journal of Insect Science, 10(144), 118, 2010.

[11] Okrouhla, M., Portravne ekologieka studie slunecka cheilomenes sulphurea, Ph. D. Thesis, Charles University, Prague, 1983.

[12] Pearl, R., The Biology of Population Growth, Knopf, New York, 1925.

[13] Shehata, T. E. and Marr, A. G., Effect of nutrient concentration on the growth of Escherichia Coli. J Bacteriol, 107, 210-216, 1971.

[14] Slama, K. and Jedlicka, P., Respiratory metabolism of the pea aphid, Acyrthosiphon pisum, (Hemiptera: Aphididae), Eur. J. Entomol., 109, 491-502, 2012.

[15] Smith, K. M., Plant Virus, Springr, Netherland, 1977.

[16] Smith, M. A. H., Mackay, P. A. and Lamb, R. J., Temperature modulation of photoperiodism: an adaptation for long distance dispersal in the aphid, acyrthosiphon pisum (Hemiptera: Aphididae), The Canadian Entomologist, 145(3), 302-316, 2013.

[17] Volterra, V., Variation and fluctuation in the number of coexisting animal species, The Golden Age of Theoretical Ecology: 19231940, Lecture Notes in Biomathematics 22, 1978, Springer Verlag, Berlin ( Authors: Scudo FM, Ziegler JR), 1927. 